\title{
EDUCAÇÃO E MÚSICA: UMA LEITURA PELA ÓTICA DA INDÚSTRIA CULTURAL
}

\author{
Gabriel Amaral da Silva ${ }^{1}$, Joyce de Fátima Morais ${ }^{2}$, Roseli Gall do Amaral da Silva ${ }^{3}$ \\ ${ }^{1}$ Centro Universitário de Maringá - UniCesumar, Maringá, PR. ${ }^{2}$ Universidade Estadual de Maringa - UEM, Programa de \\ Pós-Graduação em Educação, Maringá, PR. ${ }^{3}$ Universidade Tecnológica Federal do Paraná - UTFPR, Apucarana-PR. E- \\ mail: gabriel100j@hotmail.com
}

\section{RESUMO}

Esse artigo pretende discutir os elementos que incorporam os estereótipos na sociedade moderna para a construção da identidade do sujeito permeada por uma razão instrumental, voltada à objetificação e coisificação da subjetividade. Considerando a música como um conteúdo que carrega ideologias, pretende-se investigar qual o conteúdo ideológico subliminar na música, traduzida na cultura industrializada, objetivando compreender o que está sendo transmitido, e qual o reflexo que esses elementos englobam e disseminam aos indivíduos, tendo como fundamentação teórica a leitura da indústria cultural proposta por Adorno (1903-1969) e Horkheimer (1895-1973).

Palavras-chave: Educação; Música; Indústria Cultural.

\section{EDUCATION AND MUSIC: A READING BY THE OPTICS OF THE CULTURAL INDUSTRY}

\begin{abstract}
This article intends to discuss the elements that incorporate the stereotypes in modern society for the construction of the identity of the subject permeated by an instrumental reason, focused on the objectification and subjectification of subjectivity. Considering music as a content that carries ideologies, it is intended to investigate the subliminal ideological content in music, translated in the industrialized culture, aiming at understanding what is being transmitted, and what the reflection that these elements encompass and disseminate to individuals, having as theoretical basis the reading of the cultural industry proposed by Adorno (1903-1969) and Horkheimer (18951973).

Keywords: Education; Music; Cultural Industry.
\end{abstract}




\section{INTRODUÇÃO}

A sociedade moderna tem enfrentado uma frenética transformação frente às tecnologias e ao seu poder de evolução. São milhares de informações, produtos, invenções e mercadorias que chegam ao consumo de uma forma desenfreada, e ilimitada. A midiatização e a estética, ao tornarem-se cultura, transmitem uma identidade nacional e global, de forma a contribuir na formação cultural de indivíduos de diferentes regiões, culturas, etnias e classe social. Diante disso, percebe-se que a cultura ganha uma nova identidade de reprodução, a teoria do valor, e ainda um comprometimento do sentido. E perde seu sentido real, o de relatar as expressões de um povo, do senso coletivo, um sentido histórico-social, que se compromete na transmissão de valores, modos de viver e as experiências de uma geração a outra, focando em seus ideais, princípios, e que de certa forma apresenta uma continuidade.

Nesse processo, a educação formal vincula-se com as transformações vivenciadas pela sociedade de forma efetiva, adquirindo a identidade da cultura que lhe é imposta, e não somente o processo histórico construído ao longo dos tempos pelos sujeitos. A cultura e a ética são apropriadas pela inculcação de valores, perde-se assim a reflexão da arte pelo processo da mediação, que poderia romper com a cadeia do imediatismo, através da criticidade e da busca pelo conhecimento.

Dessa forma, Adorno (1995) em suas reflexões, considera esse modo de vivência como a manipulação dos sujeitos pelo consumo que determina a vontade individual, com o discurso de individualidade, mas que em sua forma, nega o ego, fragiliza-o para então dominar sobre ela qual esse ideal de individualidade, quando que, cria e recria um estereótipo geral, mascarado pela subjetividade. A sociedade do consumo cria satisfações para seus consumidores, assumindo uma dimensão mercantil de troca e a lógica da lucratividade sobre o outro, ao invés do princípio antigo de repassar às gerações futuras seus conhecimentos.

Nessa criação da satisfação, o ser humano não sofre a emancipação, de suas vontades, preferências, subjetividades, mas aflora a passividade como um reflexo dessa cultura mercantilizada, ao passo que a crítica a essa cultura se dá pela fato da negação da arte como uma articulação de mobilização, de uma expressão de revolta que era tão presente nos séculos XVIII e $\mathrm{XIX}$, com as revoluções que marcaram as transformações na estrutura da sociedade, e principalmente o lluminismo que surgiu e se firmou para a transformação do pensamento humano.

Na sociedade moderna, o que se nota é um esfriamento desse processo, um esvaziar da necessidade de mudança política, social, e principalmente de pensamentos e reflexões. Quando Adorno traz a crítica para passividade e a indústria cultural, essa crítica refere-se ao empobrecimento do intelectual e da capacidade de criar mudanças para o desenvolvimento da sociedade.

Fazendo um resgate para a Revolução Francesa, por exemplo, essa medida, serviu a população da época como uma fuga, do que os aprisionavam, uma mudança de pensamento e modo de vida, que de certa forma, estava presente uma luta de classes, mas não apenas, uma superação de dominantes e dominados, muito além disto, estava em questão a liberdade para pensar, refletir, criticar e agir sobre a sociedade de forma eficaz.

A leitura que se tem atualmente é de uma sociedade que está dominada não por classes, interesses, religião ou sistema, mas pela alienação do pensamento, em que pensar, já seria capacidade de alto nível, possível apenas a Indústria Cultural, que então massifica seu ideal, dando forma, e embrutecendo o conhecimento.

Na forma de organização social moderna o homem necessita entender que tem sua parte na construção da história. De forma que esse entendimento pode ser traduzido na emancipação do homem do sistema escravista. O esclarecimento nesse sentido proposto por Adorno é aquilo 
que traz ao homem a capacidade de se emancipar. Desfazendo o controle do homem sobre o próprio homem.

As mudanças sociais no processo de produção podem influenciar os interesses e determinações históricas, perde-se o domínio sobre o que se produz e sua quantidade. Produz-se para uma satisfação imediata, o que gera um círculo vicioso, pois o produto em si vale até o momento em que satisfaz o verdadeiro produto dessa sociedade, a saber o sujeito histórico, social, que satisfeito, gera uma nova frustração, e busca novos produtos, e nessa rotina, se cria, produz e reproduz. Não mais dando conta em satisfazer por longo prazo, talvez pelo fato dessa frustração do ser humano não estar diretamente envolvida com o produto industrializado e comercializado, mas com sua vida presa, seu pensamento incapaz de perceber a necessidade de mudança.

\section{METODOLOGIA}

Para a construção da pesquisa utilizou-se um levantamento bibliográfico com abordagem qualitativa. Conforme Lima e Mioto (2007) a pesquisa bibliográfica possibilita um amplo alcance de informações, auxiliando também na construção, ou na melhor definição do quadro conceitual que envolve o objeto de estudo proposto.

\section{RESULTADOS}

Em todo esse processo pelo qual tem-se desenvolvido a modernidade, deve-se focar os olhares para um ponto central, preciso em todo tempo, por todas as sociedades, a educação, formadora de opinião e transmissora do saber. Nesse princípio, o que se busca é entender qual tem sido a função social da escola nesse contexto da cultura industrial, suas interferências e influências. Como afirma Leontiev (2004), o movimento da história só é possível, com a transmissão, às novas gerações, das aquisições da cultura humana, isto é, com a educação.

Como já dito antes, o próprio ato de educar em si é uma arte, que não se vende, mas se ganha e se dá por meio de um processo dialético e de mediação, de um sujeito com outro, ou de instrumentos, para o desenvolvimento pleno do indivíduo, na verdade para que este seja capaz de refletir sobre sua sociedade, e correlacioná-la com outras contemporâneas e antigas, a fim de agir sobre ela de forma a modificá-la se necessário. "A educação tem sentido unicamente como educação dirigida a uma auto-reflexão crítica (ADORNO, 1995, p. 121)". Mas a cultura moderna tem levado a irracionalidade, à uma pseudo-formação, um formação falsa e crua.

É importante esclarecer que as teorias críticas não vêm para apresentar saídas e resultados sobre as verdades, mas vem falar, esclarecer a verdade. Nesse sentido, não se quer dizer que não há uma forma de intervenção para esse processo, mas sim que ele já é um processo efetivo. Pois quando o homem toma o conhecimento para si, ele se liberta, mas vê-se preso a esse sistema, nessa realidade da cultura mercantilizada. Conforme Adorno (1995), essa cultura moderna é propriamente a cultura da manipulação, o termo cultura em si perdeu seu verdadeiro sentido, e sua real função a de construir a história de uma época, através de suas produções livres, sua arte que reflete as lutas, conquistas, desafios e a própria e simples vida cotidiana das pessoas.

A massificação da cultura é a própria cultura administrada, por quem só quer conservar, e não mais criar, apenas repetir o que deu certo, em várias outras formas, e negando ao ser humano a capacidade de observar esse processo. Essa dimensão de administrar a cultura compromete a construção da vida comunitária e o estético, de forma que a imagem incorpora os interesses da sociedade ao indivíduo, talvez por esse motivo, vê-se tanta gente igual, com a mesma roupagem, ouvindo o mesmo tipo de música, e se achando tão diferentes. Já se perdeu o olhar atento, a percepção, as funções psicológicas superiores, de que faz referência Vigostky (1991).

É nesse sentido que deve se repensar a educação, para uma formação reflexiva, plena, e não para a salvação da humanidade, mas em prol da arte de ensinar, com a finalidade de resgatar 
a arte em aprender, o entusiasmo pelo conhecimento, a emancipação. Pois "a superioridade do homem está no saber (ADORNO; HORKHEIMER, 1947, p. 5)".

A educação contemporânea precisa compreender o processo da constituição da indústria cultural para então se apropriar de mecanismos que desmistificam-a. Enquanto que percebe-se a limitação de visão de mundo atrelado ao totalitarismo da indústria cultural, que não mais distingue a arte superior, feita a partir de conflitos e filosofias de vida, da arte popular, feita a partir da lucratividade sem propósitos históricos, como por exemplo tão exacerbado das atuais melodias de canções feitas semelhantes, excluindo tudo o que for diferenciado a essas.

A escola tem sido na verdade uma expressão da cultura massificada. Não há o que se discutir sobre uma forma geral de implementação que mude essa realidade, mas, é necessário compreender essa defasagem e agir sobre ela, de uma forma dialética efetiva, buscando elementos de compreensão e atitudes responsáveis intelectualmente, para o crescimento educacional. Com a finalidade de fazer cultura não para o entretenimento, mas para o conhecimento, que diga-se é o papel social da educação. Como adverte Adorno: "Nos casos em que a cultura foi entendida como conformar-se à vida real, ela destacou unilateralmente o momento de adaptação, e impediu assim que os homens se educassem uns aos outros (ADORNO, 1996, p. 390)".

Não mais está em questão a luta de classes, a força dos dominantes sobre os dominados, pois esse papel cabe agora a própria cultura que se estruturaliza em dominar, de forma que ela induz e prodoniza, fazendo manter um modelo padrão social, que chegou até a educação, ou seja um modelo de organização social.

Ao se tomar por princípio que o sistema da indústria cultural reorienta as massas, pouco thes permitindo a evasão do cerco que exerce ao lhes impor esquemas de comportamento, os quais exploram a fraqueza do ego social, justifica-se compreender criticamente os seus mecanismos ardilosos (FABIANO, 2003, p. 496).

Considera-se que a partir do momento em que o sujeito assume os pressupostos da ideologia mercantilizada, se torna parte dessa sistematização, um pragmatismo típico da revolução industrial. De forma que o conformismo substitui a consciência e a indústria cultural produz a distração.

Assim retomar a função específica da educação, para que ela contribua no desenvolvimento do sujeito com o propósito de que ele não se torne objeto nessa relação, e de que não se deixe ser, mas se torne apto para transformar-se na medida em que o conhecimento vai se totalizando e se tornando real em sua prática.

\section{DISCUSSÃO}

Vários são os objetos que a cultura industrial usa para sua proliferação, como já anunciado, até os palcos da educação foram influenciados por ela, dentre esses, encontra-se a literatura, quando se cria obras de ficção para desviar os olhares dos problemas econômicos e educacionais, a moda que dita padrões estéticos, a mídia que por hora cobre o entendimento real das situações e conflitos sociais, por meio, por exemplo, das novelas e falta de informações plenas, enfim há uma gama de instrumentos vinculados ao conceito que objetiva de forma direta ou não, à libertação do pensamento.

A arte musical como uma força de massa, engaja e alcança todos os níveis sociais. Para Adorno Essa percepção da degradação da arte musical, em efeito da nova manipulação dessa expressão, é constituída com a contraposição de uma arte na música que fora corrompida pelos processos inerentes ao sistema capitalista de produção: a transformação do objeto musical em mercadoria resulta na subtração da autonomia contemplativa do ouvinte. O conceito está assim especificado por acreditarem que não há uma dominação de classe sobre a outra, mas entre as classes, envolvido nelas, é de sujeito para sujeito, atingindo a cultura original. 
É nesse contexto que se afirma as teorias críticas, para a finalidade de superar esse sistema, com entendimento, solidez e com tarefa de dar conhecimento muito mais do que informação, entender os limites da cultura mercantilizada, pensar em práticas emancipatórias. Quando se faz um paralelo entre as músicas de raiz, seja de qual estilo for, com as músicas da atualidade, o tom da narrativa expressa um empobrecimento humano e cultural. É uma falsa experiência social.

[...] a audição regressiva constitui um inimigo impiedoso não só dos bens culturais [...], mas também da função antiguíssima e sagrada da música como instância de sujeição e repressão dos instintos. [...] Embora a audição regressiva não constitua sintoma de progresso na consciência da liberdade, é possível que inesperadamente a situação se modificasse, se um dia a arte, de mãos dadas com a sociedade, abandonasse a rotina do sempre igual. Para esta possibilidade a música produziu um modelo: não a música popular, mas a artística (ADORNO, 1996b, p. 106-107).

Há uma ideologia sendo transmitida por meio dessas canções, não é difícil perceber que estas relatam historietas de amor, amores que não deram certos, sentimentos de culpa, sentimentos de vanglória por ter conquistado um grande amor, uma liberdade de se viver a vida sem se importar com ninguém, como se o amor, a paixão fosse a força principal da existência humana, e nada mais importa.

Essa filosofia amorosa que era tão presente no estilo sertanejo, hoje ganha uma força maior, mas ao cruzar as ruas e avenidas é impossível não perceber o rock, tão conceituado pelas denúncias que faz, o samba, o funk, o pop, os estilos musicais comprometidos com que se lucra. Poucas produções expressam a vida social, a experiência social, a luta por condição moral, mas uma ordem em vender a satisfação imediata, de alegria e de consolo pela música que se vendo pelo conceito de traduzir o que quer dizer. Adorno considera que "ao invés de entreter, parece que tal música contribui ainda mais para o emudecimento dos homens, para a morte da linguagem como expressão, para a incapacidade de comunicação (ADORNO, 1996a, p. 67,)".

Há na verdade uma necessidade em criar no indivíduo uma identificação imediata, ou seja, ele se torna o próprio produto. E não existe um compromisso com a noção de arte, e do conhecimento como mecanismos estéticos que refletem a sociedade e os valores culturais, e por ser assim, abortam a necessidade de compreendê-la, basta consumir.

A moditização da música e esse empobrecimento cultural que se tem visto, nada mais são do que o reflexo da forma ou má forma que temos visto o mundo social. É um olhar desatento, uma falta em se situar no tempo e espaço histórico, a falta de elementos que elevam a alma e o conhecimento.

\footnotetext{
Orientada pela lógica capitalista, a sociedade incorpora e se submete ao fetiche, empreende criações destrutivas, inventa desejos, elabora e tira proveito de novas capacidades, modifica o uso e representação do tempo e do espaço, revoluciona modos de vida. Em meio a rapidez com que as mudanças se processam, o indivíduo não mais reconhece seu ambiente de individuação, não sabe da sua própria identidade (FABIANO; PALANGANA, 2013, p. 7).
}

À medida que os princípios ideológicos criam identidade no indivíduo, então os princípios já cumpriram seu papel. E no momento em que há essa identificação com a ideologia há um comprometimento da percepção. Em uma comparação com uma musicalidade bem articulada, com conteúdos de social, e uma outra que se faz pela cópia da melodia e com o propósito de vender apenas, é possível perceber que a música bem construída te traz reflexão, o que te desconcerta para então, em um certo momento de construir novamente, com novos paradigmas, enquanto que a música de massa vem pronta e acabada apenas para ser internalizada, são nas palavras de Adorno (1996a) mercadorias musicais padronizadas. 


\section{CONCLUSÃO}

Mesmo existindo na mídia esse caráter pedagógico padronizado com relação a cultura, é importante citar que considerando os estudos culturais e, posteriormente o pensamento contemporâneo francês, existe nessa tendência da indústria de massificar estilos culturais um processo muito mais complexo do que apenas uma manipulação estática de classes altas sobre as baixas.

Uma das contribuições dos estudos da pós modernidade é exatamente sobre esse reconhecimento da cultura como algo móvel, que acompanha as manifestações culturais. Mesmo com esse viés de capitalizar movimentos emergentes, a indústria não manipula ou domina como é suposto em teorias pós guerra como os da escola de Frankfurt. Por outro lado, podemos encontrar nessas relações de poder um processo de neutralização, no momento em que a mídia de certa forma veicula o conteúdo que tem público para o consumir, formando assim uma espiral interativa entre a massa e a mídia, algo que exige participação popular, embora prevaleça uma iniciativa gerada pela visão capitalista.

\section{REFERÊNCIAS}

ADORNO, T.L. W. Teoria Estética. ed 70, Lisboa/ Portugal. 2008.

. Teoria da semicultura. Trad. Newton Ramos de Oliveira. Educação \& Sociedade. Campinas: Papirus. Ano. XVII. 1996a.

. O Fetichismo da Música e a Regressão da Audição. São Paulo. ED. NOVA CULTURAL

LTDA. 1996b.

. Educação e Emancipação. Rio de Janeiro, Paz e Terra, 1995.

ADORNO, T.L.W.; HORKHEIMER, M. Textos escolhidos. In: Os pensadores. Trad. Zelijko Loparic' e outros. São Paulo: Nova Cultural,1991.

Dialética do esclarecimento: fragmentos filosóficos. Trad.: Guido A. de Almeida. RJ:

Zahar, 1985.

BENJAMIM, W. Mágia e técnica, arte e política: ensaios sobre a literatura e história da cultura. Trad. Sérgio Paulo Rouanet. 7. ed. São Paulo: Brasiliense, 1994.

DUARTE, R. A desartificação da arte segundo Adorno: antecedentes e ressonâncias. In: ArtefilosofiaFilosofia. Teatro. Música. Ouro Preto, n 2. 2007

FABIANO, L. H. Adorno, arte e educação: negócio da arte como negação. Educação \& Sociedade. Campinas, vol.24, n.83, p. 495-505, 2003.

FABIANO, L.H.; PALANGANA, I.C. Identidade e cultura mercantilizada. 2013. Disponível em http://23reuniao.anped.org.br/textos/2013t. acesso em dez de 2017.

LEONTIEV, A. O desenvolvimento do Psiquismo. 2a ed. São Paulo: Centauro, 2004.

LIMA,T.C.S.; MIOTO, R.C.T. Procedimentos metodológicos na construção do conhecimento científico: a pesquisa bibliográfica. Revista Katálysis, v. 10, 2007. 
VYGOTSKY, L.S. A formação social da mente: o desenvolvimento dos processos psicológicos superiores. Tradução de José Cipolla Neto, Luis Silveira Menna Barreto, Solange Castro Afeche. 4. ed. São Paulo: Martins Fontes, 1991. 